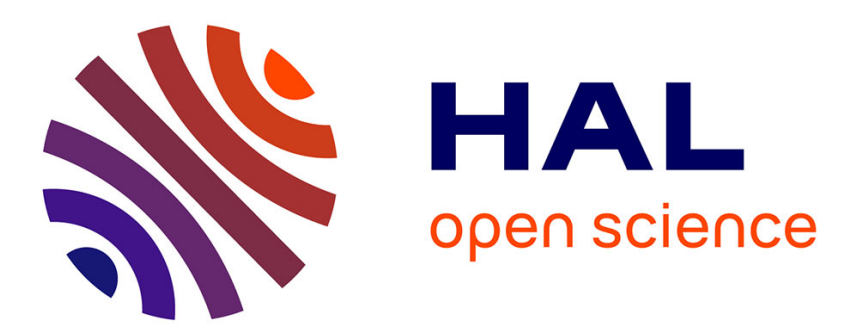

\title{
Masonry Walls under Membrane or Bending Loading Cases: Experiments and Discrete Element Analysis
}

\author{
Tan Trung Bui, Ali Limam
}

\section{To cite this version:}

Tan Trung Bui, Ali Limam. Masonry Walls under Membrane or Bending Loading Cases: Experiments and Discrete Element Analysis. The Eleventh International Conference on Computational Structures Technology, Sep 2012, Dubrovnik, Croatia. Paper 119, 10.4203/ccp.99.119 . hal-00802263

\section{HAL Id: hal-00802263 https://hal.science/hal-00802263}

Submitted on 19 Mar 2013

HAL is a multi-disciplinary open access archive for the deposit and dissemination of scientific research documents, whether they are published or not. The documents may come from teaching and research institutions in France or abroad, or from public or private research centers.
L'archive ouverte pluridisciplinaire HAL, est destinée au dépôt et à la diffusion de documents scientifiques de niveau recherche, publiés ou non, émanant des établissements d'enseignement et de recherche français ou étrangers, des laboratoires publics ou privés. 


\title{
Paper 119
}

\section{Masonry Walls under Membrane or Bending Loading Cases: Experiments and Discrete Element Analysis}

\author{
T.T. Bui and A. Limam \\ University of Lyon, INSA de Lyon, LGCIE, France
}

\begin{abstract}
This research is conducted to gauge the efficiency of the discrete element method (DEM) to reproduce the behaviour of masonry walls submitted to in plane or membrane loading, and out of plane or bending loading cases. The efficiency of the DEM is estimated for all nonlinear behaviour, from the appearance of cracks and associated stress redistributions, cracks propagation, until the failure mechanism related to the ultimate load. The robustness is also evaluated, knowing that different geometrical configuration and loading cases are considered which permits the effects of the main parameters to be gauged such as geometrical dimensions of the walls, the nature and size of the built blocks, as well as the loading case. Several experimental tests are simulated, some from the literature, and the others were conducted in our laboratory. The numerical simulation investigation using the discrete element method is conducted using the 3DEC code. For all the cases, a quite good agreement between the numerical and the experimental results was obtained, which confirms the efficiency and robustness of the DEM method for the quasistatic loading configurations here considered. There is good correlation between the experiments and the simulations for the main characteristics, such as the crack localisation, the bearing capacity of the structure and the failure mode.
\end{abstract}

Keywords: discrete element method, masonry walls, membrane loading, bending loading.

\section{Introduction}

Several research have been conducted to simulate the behaviour of masonry structures, some by using continuum or 'smeared-crack' models such as that proposed by Lourenco [1-2] and Rots [3], and others using discontinua based approach or discrete element models [4-5]. The development of DE models has enriched the set of tools available for analysis of masonry structures. In DEM, the 
heterogeneous nature of masonry and the discontinuity at block interfaces can be well described. The main domain of application of DE models to masonry has been in the study of structures that fail predominantly by mechanisms in which block deformation plays little or no role at all. In particular, DEM allows simulating large movements with complete block separation, which traduce substantial changes in stress distribution. The main appeal of this approach lies in its ability to reproduce complex behaviours even if elementary failure mechanisms associated to simple physical input parameters are considered. Interactions between blocks may be represented simply by forces, and fracture is simply modelled by the progressive breakage of bonds, in tension or shear. Computational developments in the field of DEM have allowed these techniques to be progressively applied in the failure analysis of structural components and larger structures, under static or dynamic loading, but validation of DE modelling in face of experimental data still continues to be a key task. In this research, discrete element modelling is illustrated by applications to various masonry problems where in plane loading, out of plane loading, or both, are considered.

\section{Discrete element method}

The 3DEC (3-Dimensional Distinct Element Codes) code developed by Itasca [12], based on the distinct element method is used for the simulation. The discontinuous element model is represented as an assemblage of discrete blocks. The discontinuities are regarded as distinct boundary interactions between these blocks; joint behavior is prescribed for these interactions. Individual blocks behave as either rigid or deformable material. The deformable blocks are further divided into a finite number of constant strain tetrahedral elements.

a)

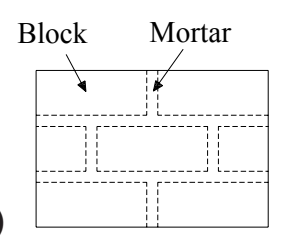

b)

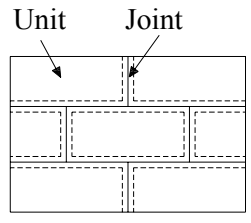

c)

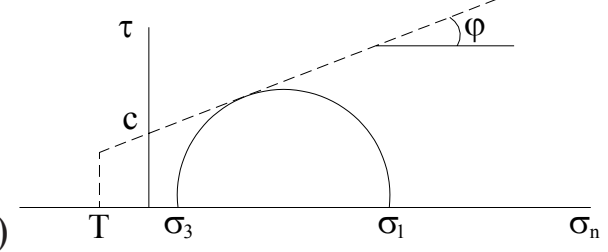

Figure 1:-a) Detailed micro-modelling masonry wall; b) Simplified micromodelling masonry wall; c) Mohr-Coulomb model of joint with tension cut-off.

For the simulation, and depending on the problem, rigid or deformable blocks are utilized, in the last case the behavior is considered elastic. The masonry wall is simulated by a simplified micro modeling. The mortar joints are not modeled directly as elements, but indirectly by an interface law between the blocks. The size of one unit is the sum of block size and mortar thickness (Figure 1b). The interface obeys the Mohr-Coulomb joint model with tension cut-off. This joint constitutive model considers both shear and tensile failure, and joint dilation is included. In the elastic range, the behavior is governed by the joint normal and shear stiffness, $k_{n}$ and $k_{s}$ : 


$$
\{\sigma\}=[K]\{u\} \quad \text { or } \quad\left\{\begin{array}{l}
\tau_{s} \\
\sigma_{n}
\end{array}\right\}=\left[\begin{array}{ll}
k_{s} & 0 \\
0 & k_{n}
\end{array}\right]\left[\begin{array}{l}
u_{s} \\
u_{n}
\end{array}\right]
$$

where: $\sigma_{n}$ : normal loading; $u_{n}$ : normal displacement

$\tau_{s}:$ shear stress; $u_{s}:$ shear displacement.

The maximum shear force allowed is given by: $\tau_{\max }=c+\sigma_{n(\max )} \cdot \tan \varphi$, where $\mathrm{c}$ and $\varphi$ are the joint cohesion [stress] and friction angle. After this peak shear strength is reached, a drop in strength occurs abruptly until a residual strength obtained by $\tau_{\text {res }}=\sigma_{n(\max )} \tan \varphi($ Figure $2 \mathrm{a})$.
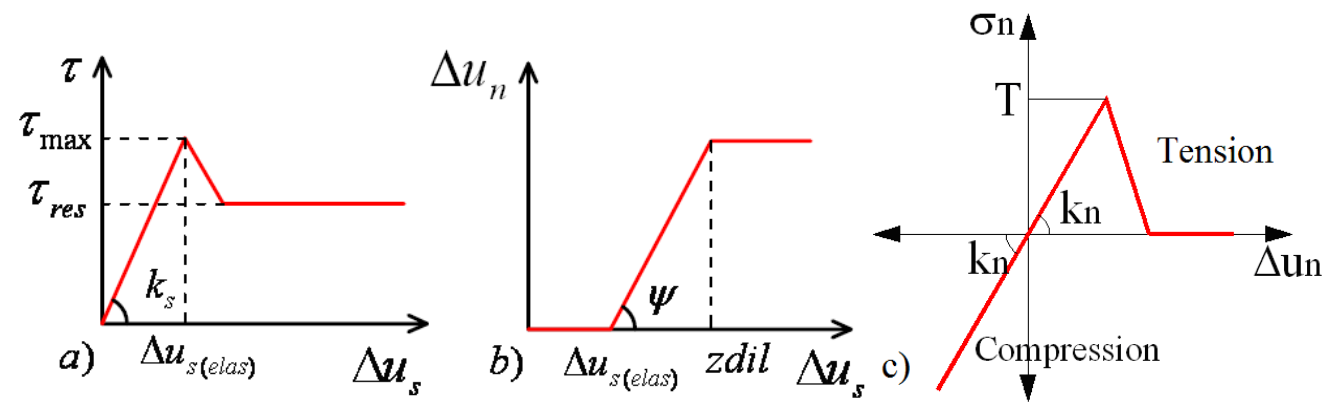

Figure 2: Joint behaviour: a) Mohr-Coulomb slip model; b) Bi-linear dilatant model; c) Behaviour under uniaxial loading.

As indicated in Figure 2b, the joints begin to dilate when the joint fails in shear, at $\Delta u_{s(e l a s)}$ shear displacement. This displacement leads to a dilation of:

$$
\Delta u_{n}(\text { dilatation })=\Delta u_{s} \tan \psi
$$

where $\psi$ is the dilation angle.

The normal force must be corrected to account fort the effect of dilation:

$$
\sigma_{n}(\text { dilatation })=\sigma_{n}+k_{n} \cdot \Delta u_{n}(\text { dilatation })=k_{n} \cdot \Delta u_{n}+k_{n} \cdot \Delta u_{s} \tan \psi
$$

Dilatancy is a function of the direction of shearing. Dilatancy increases if the shear displacement increment is in the same direction as the total shear displacement, and decreases if the shear increment is in the opposite direction. The extension occurs until the limiting shear displacement (zdil) is reached. The joint behaviour under uniaxial loads is plotted in Figure 2c, where $\mathrm{T}$ is the joint tensile strength.

\section{Validation in the case of in plane loading}

In order to validate the efficiency of distinct element method to predict the collapse mechanism, the first campaign of tests, corresponds to the case of a vertical wall subjected to its dead load as in plane loading and to a settlement of a part of the 
foundation. Boundary condition corresponds to local support of the bottom wall; the other extremities of the wall are free. In addition to the membrane loading, a partial loss of the simply supported bottom boundary condition is applied. This loading traduces the collapse of the soil support. In the experimental tests, a controlled displacement (constant velocity) is applied on a part of the first level of the dry brick masonry, this induces settlement. No mortar was used in the models, which means that the shear strength along the joints was given purely by friction. This allows the tests can be carried out with quite simple method and can be repeated easily. This type of test is a simplified approach from the ground movement, soil-structure interaction was not considered. These tests allows to observe various modes of wall failure, depending on the loss of boundary conditions envisaged (size and location) and depending on the bricks arrangement. The tested walls, of size $1.575 \times 1 \times 0.22 \mathrm{~m}$, consists of bricks of dimensions $22 \times 10.5 \times 5 \mathrm{~cm}$. The density of the brick is $2200 \mathrm{~kg} / \mathrm{m}^{3}$ and the angle of friction between two bricks obtained experimentally is $38^{\circ}$. Test consists of settlement on a portion of wall to a height of $14 \mathrm{~cm}$. Simulations were carried out with the assumption of zero cohesion and zero tensile strength which may approach the case of dry joints. A low normal rigidity $\mathrm{k}_{\mathrm{n}}=1.96 \mathrm{~N} / \mathrm{mm}^{3}$ and shear stiffness $\mathrm{k}_{\mathrm{s}}=0.82 \mathrm{~N} / \mathrm{mm}^{3}$ was used for joints.

The openings of joints, fracture surface and location, observed experimentally (Figure 3a) are corroborated by the numerical simulation (Figure 3b). A second configuration of the mesh (Figure 3c) gives us the same deformations and failure modes, which allow us to confirm the robustness of the approach in the case of the simple superpositions of discrete elements, thus highlighting the pertinence of Coulomb law for these configurations, where actually, the interaction are reduced to sliding contact. This example has shown that the DEM, even a very simplified one, may have significant advantages in failure analysis, as it captures very effectively observed patterns.

a)
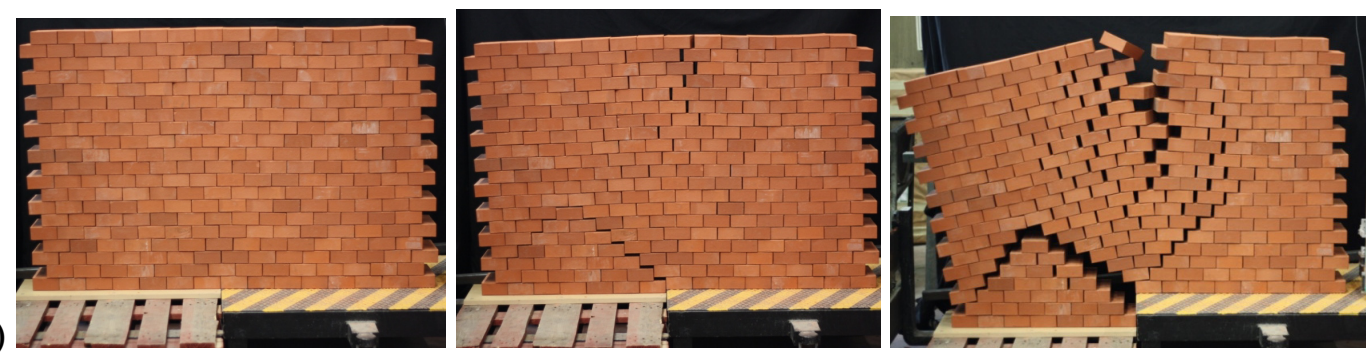

b)

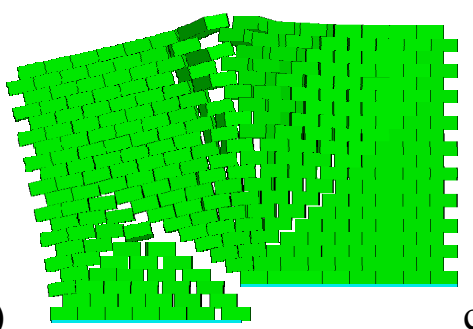

c)

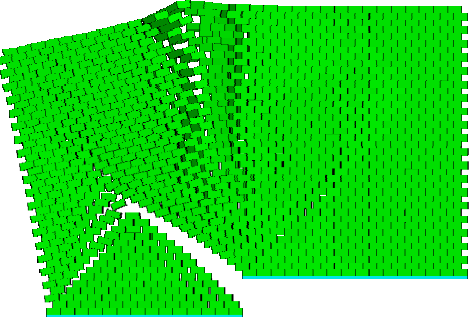

Figure 3: Brick wall with partial loss of bottom boundary conditions: test/modelling. 
The validation, still in the case of dry joints, is then conducted in the case of in plan loading where shear and axial compression are combined. The examples discussed here result from tests available in literature. Lourenço \& al [6] tested a certain number of walls having the same size of $1 \times 1 \times 0.2 \mathrm{~m}$ and made of $200 \times 100 \times 200 \mathrm{~mm}$ dry stones. An embedded concrete beam at the bottom of the wall was used to ensure boundary conditions. One fixed block was installed at the left bottom of wall to block horizontal sliding. The loading history corresponds to first the application of the axial compression at the desired level $(30,100,200$ and $250 \mathrm{kN}$ ) as pre-compression, and then the shear load is incremented until the collapse of the wall. These tests are chosen to qualify the pertinence of DEM by catching the failure mechanism as well as the associated ultimate combined in plane load.

a)
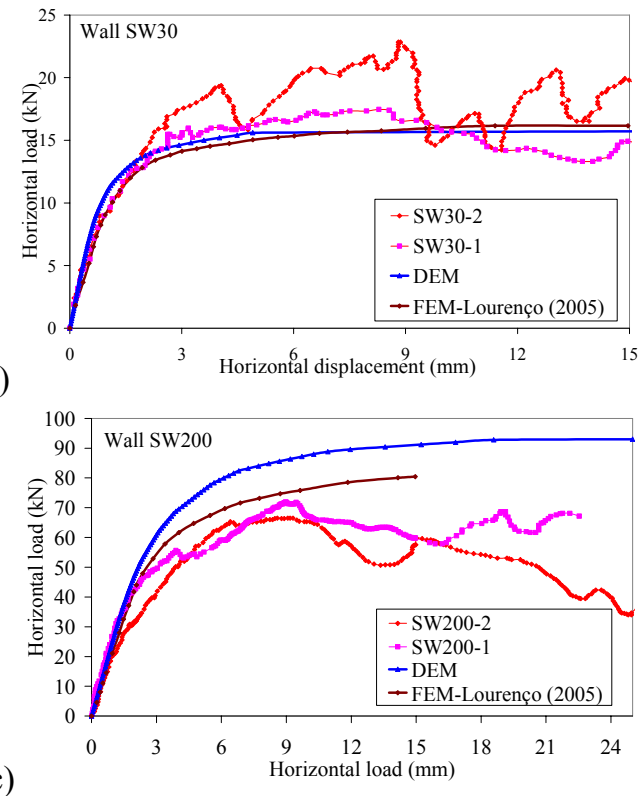

b)
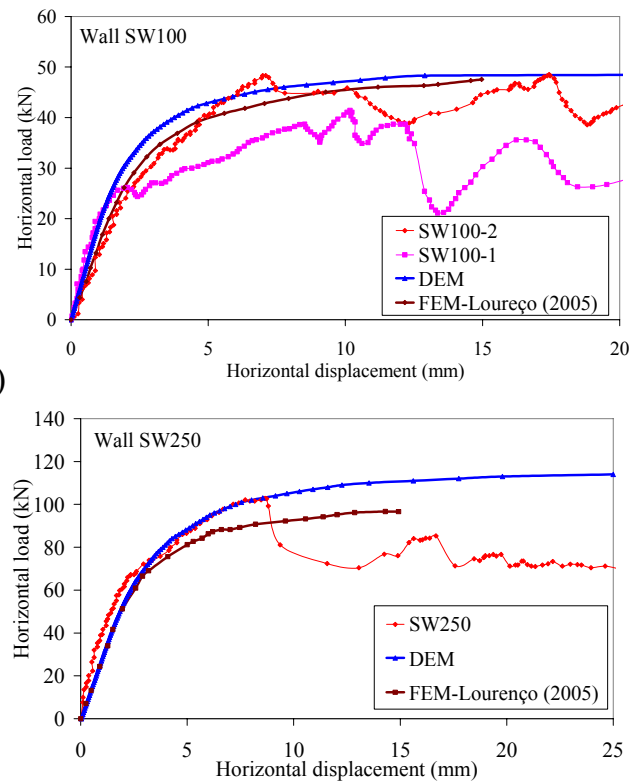

Figure 4: Load-deflection curves comparison: Experiments, DEM and FEM according to Lourenço [6]

The inelastic parameters of the dry joints like cohesion, the tensile strength, the angle of dilatancy, have a value of zero. Thus, the non-linear behaviour of the interfaces is governed by the friction angle of $32^{\circ}$. The results obtained by DEM are compared with the experimental and FE (Finite Element) numerical results of Lourenço \& al [6] in Figure 4, where the authors used the multi-surface interface model for their numerical simulations. For two specimens SW30 and SW100, the curves obtained by DEM are approximately the same as those obtained by Lourenço (Figure $4 \mathrm{a}, \mathrm{b}$ ). With increasing vertical compression up to $200 \mathrm{kN}$ and $250 \mathrm{kN}$ (SW200 \& SW250), damage in the stones was found during the experimental tests. However, the assumption of elastic behaviour for the stones adopted in DEM simulation widened the difference between the two numerical curves in the nonlinear phase: one obtained by DEM and the other obtained by finite element method (Lourenço). It is noticed, that the two approaches fails to catch the drop of the 
bearing capacity associated to the collapse, even if the maximal load is correctly approximated.

The failure modes observed on the experimental tests are similar to the results given by DEM simulation as Figure 5 showed for wall SW30. The rupture line is created by the reinforced concrete beam at the top wall, and the horizontal slip of the dry joints. This mechanism causes a diagonal crack in the wall. With increasing of vertical compression, failures in the stones are experimentally observed, due to the adopted hypothesis these failures are not reproduced within the DEM calculation.
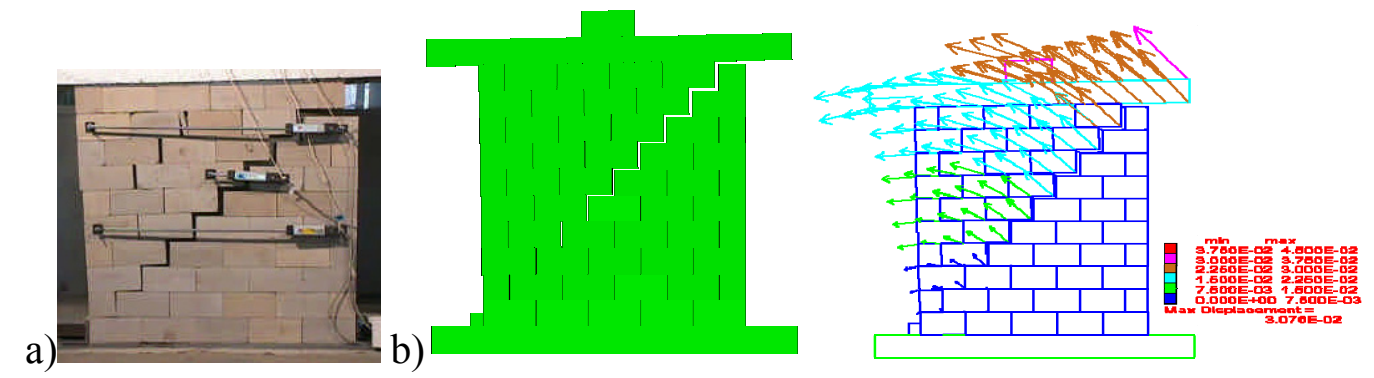

Figure 5: Failure modes: a) Lourenço test; b) Simulation by DEM (Wall SW30)

\section{Validation in the case of out-of-plane loading}

\subsection{Simulation of tests issued from the literature}

To study the case of masonry walls submitted to out-of-plane loading, the 1:5 scaled tests conducted by Restrepo-Vélez and Magenes (2009) [13] on dry stones masonry walls were simulated. These tests allow us to predict the out-of-plane failure mechanism and static collapse multiplier. Several configurations were built and tested, trying to reproduce most of the out-of-plane collapse mechanisms that have been proposed by D'Ayala and Speranza (2003) [14]. According to the tests, no mortar was used in the models.

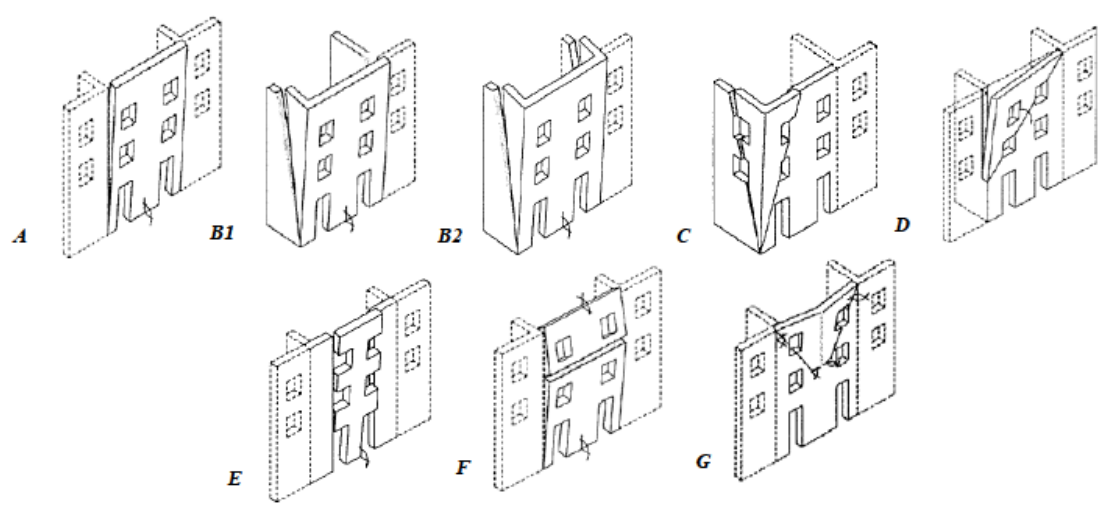

Figure 6: Out-of-plane failure mechanisms [14] 

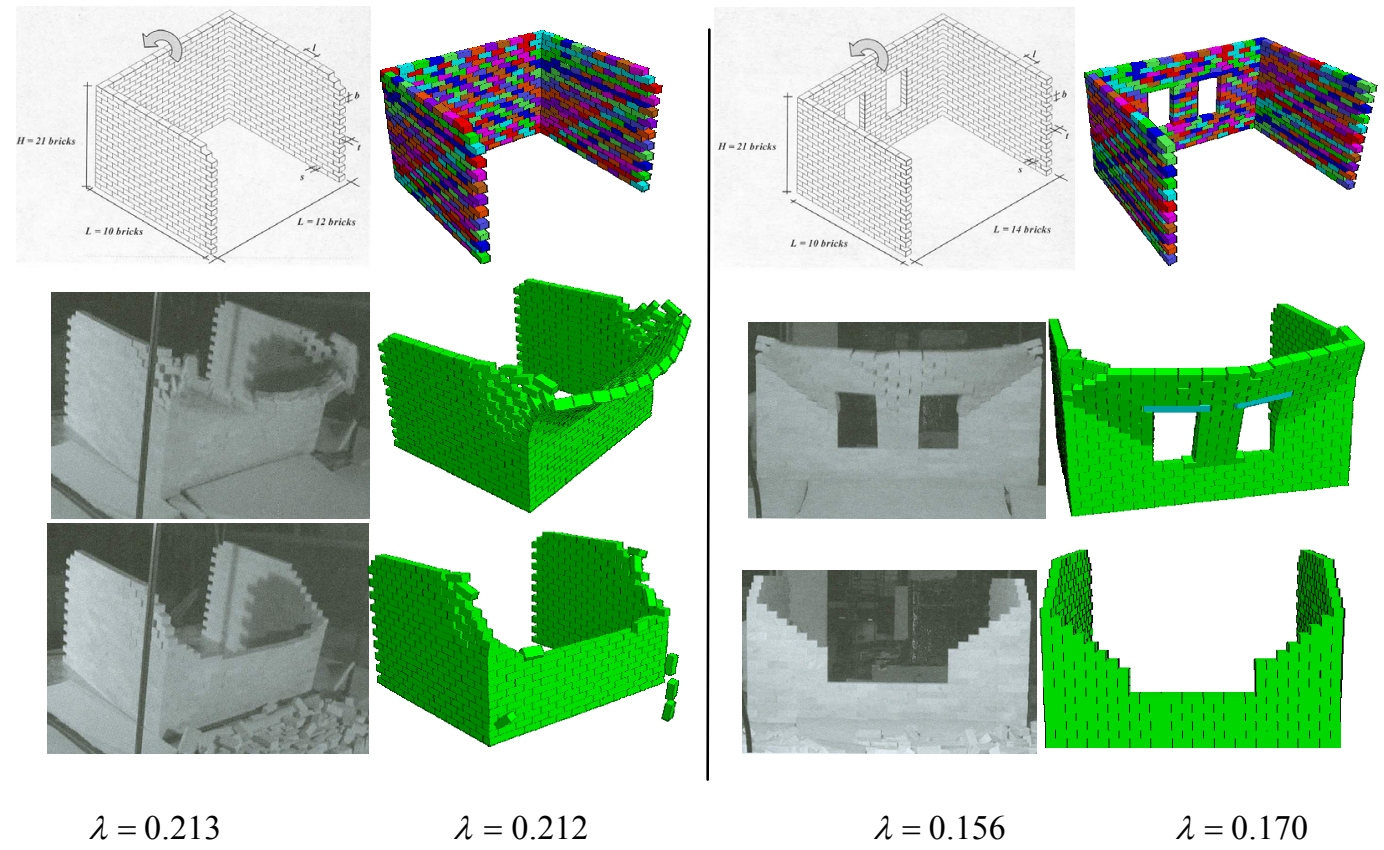

$\lambda=0.213$

$\lambda=0.212$

$\lambda=0.156$

$\lambda=0.170$

Figure 7: Comparison of collapse mechanisms: experimental tests [13] and numerical simulations (panel S10: mechanism A-B2, panel S24: mechanism A-G).

Four configurations (S10; S19; S22; S24), with and without openings, which reproduce four mechanisms of rupture $(\mathrm{A}, \mathrm{B} 2, \mathrm{D}, \mathrm{G})$, were chosen and simulated. The testing device for the static tests is a tilting platform which causes the true pushing load using gravity forces. The collapse multiplier $\lambda$ was calculated from the inclination angle of the platform. The friction coefficient of 0.67 was taken according to Restrepo-Vélez and Magenes (2009) [13]. The block size is $28 \times 80 \times 40$ $\mathrm{mm}^{3}$ (height $\times$ width $\times$ thickness). The density of each block is $2732 \mathrm{~kg} / \mathrm{m}^{3}$. Simulations with cohesion and tensile strength value equal to zero permits us to approximate mortar less joints masonry. A low shear and normal stiffness are assigned to joints $\left(k_{n}=1.96 \mathrm{~N} / \mathrm{mm}^{3} ; k_{s}=0.82 \mathrm{~N} / \mathrm{mm}^{3}\right)$.

The geometry and dimensions of four configurations were given in Figure 7 and Figure 8. The failure mechanisms obtained using distinct element method reliably predicts that of the experimental tests. Failure mechanisms in these two panels are a combination of out-of-plane deformation along the principal wall and in-plane frictional shear deformation along the return walls. A good agreement with experimental results is noticed. The critical collapse load multiplier predicted well in all configurations with a maximum variation of approximately $10 \%$ in configuration $\mathrm{S} 24\left(\lambda\right.$ experimentation $\left.=0.156 ; \lambda_{\text {simulation }}=0.170\right)$. 

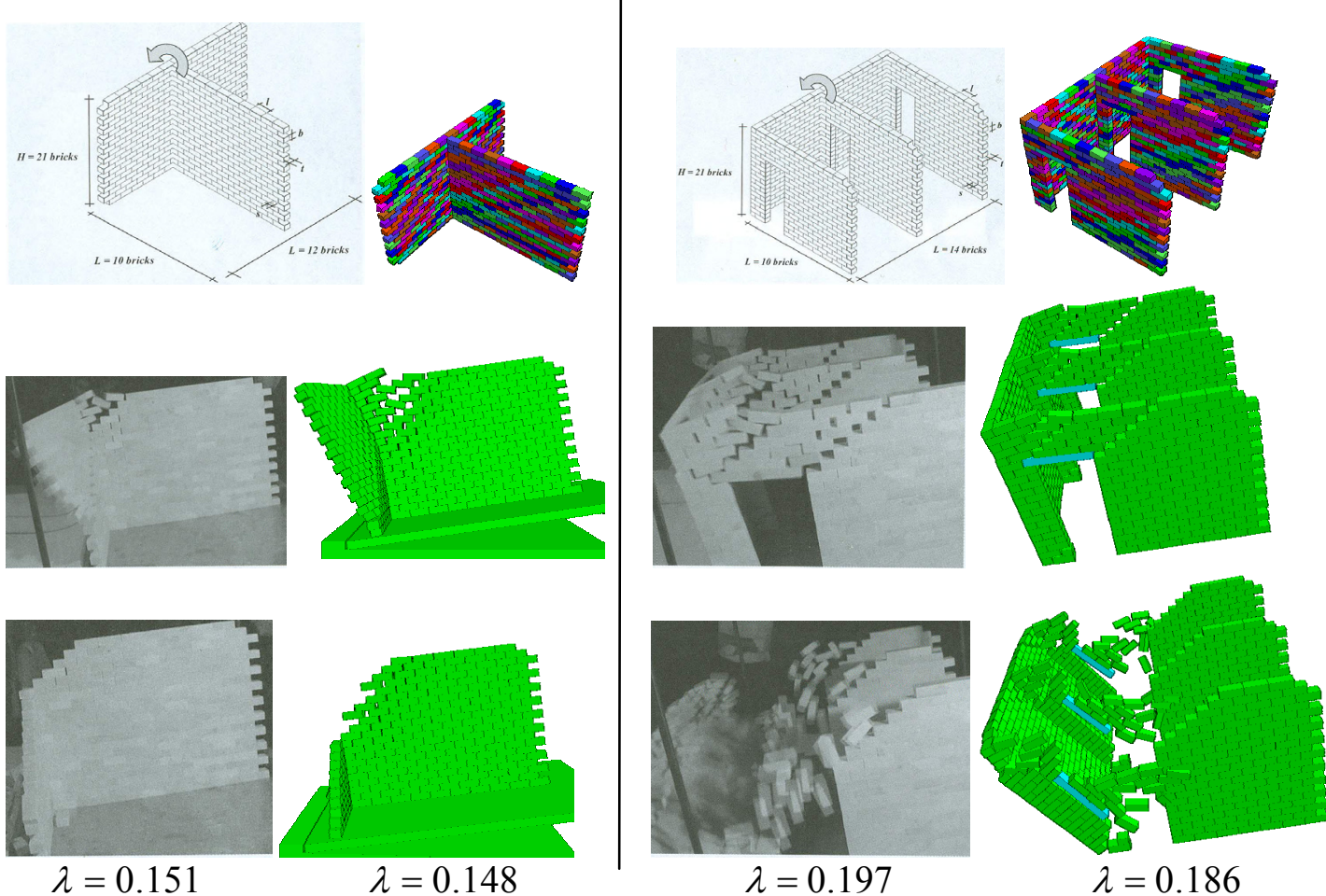

Figure 8: Comparison of collapse mechanism between experimental test [13] and numerical simulation of panel S19 (mechanism A-D) and of panel S22 (mechanism

B2).

The second example analyzed here consists of a hollow concrete block masonry beam with mortar subjected to four-point bending in different orientations. A series of 25 wallettes were carried out by Gazzola and Drysdale [8] [9]. The test specimens was created in running bond by assembling blocks of size $390 \times 190 \times 150 \mathrm{~mm}$ (height $\times$ width $\times$ thickness), with mortar thickness of $10 \mathrm{~mm}$. In the tests of Gazzola, the width of walls is constant of $790 \mathrm{~mm}$. In addition, the length of the test specimen needs to be sufficiently long to accommodate all possible modes of failure in a region of constant moment. Therefore the length of these specimens varied depending on whether the longitudinal axis (and direction of bending) was oriented at $0^{\circ}, 15^{\circ}, 45^{\circ}, 75^{\circ}$ or $90^{\circ}$ from bed joints. However, in this simulation, it would be simple to model with a chosen dimension of $790 \mathrm{~mm} \times 1600 \mathrm{~mm}$ for the mockup.
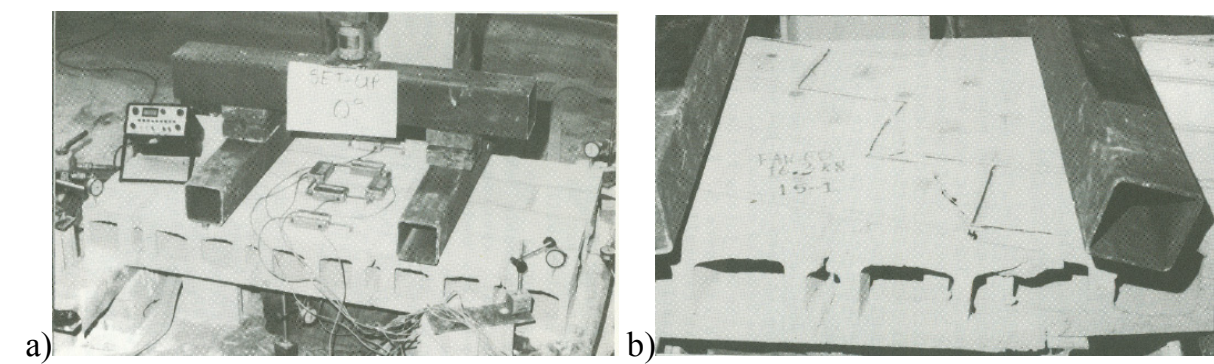

Figure 9: a) Testing of block wallettes; b) Stepped failure pattern by Gazzola and Drysdale [8] [9] 
The block behaviour is considered elastic with the Young modulus E=15GPa. The non-linear characteristics of the interfaces are chosen in order to reproduce exactly the experimental value of flexural strength reported by Gazzola and Drysdale [8] [9] (calculated by $6 \mathrm{M}_{\mathrm{u}} / \mathrm{bh}^{2}$ where $\mathrm{M}_{\mathrm{u}}$ is the ultimate bending moment, $\mathrm{b}$ and $h$ are the dimensions of the cross section of test specimen). These values are $\theta=36^{\circ}$ for the friction angle, $\mathrm{f}_{\mathrm{t}}=0.322 \mathrm{MPa}$ for tensile strength and $\mathrm{c}=1.5 \mathrm{f}_{\mathrm{t}}=0.483 \mathrm{MPa}$ for the cohesion. In figure 10, the results of the flexural tensile strength obtained by DEM are compared with the experimental and numerical ones issued from Lourenço [10] and G.Milani \& al [11] publications.

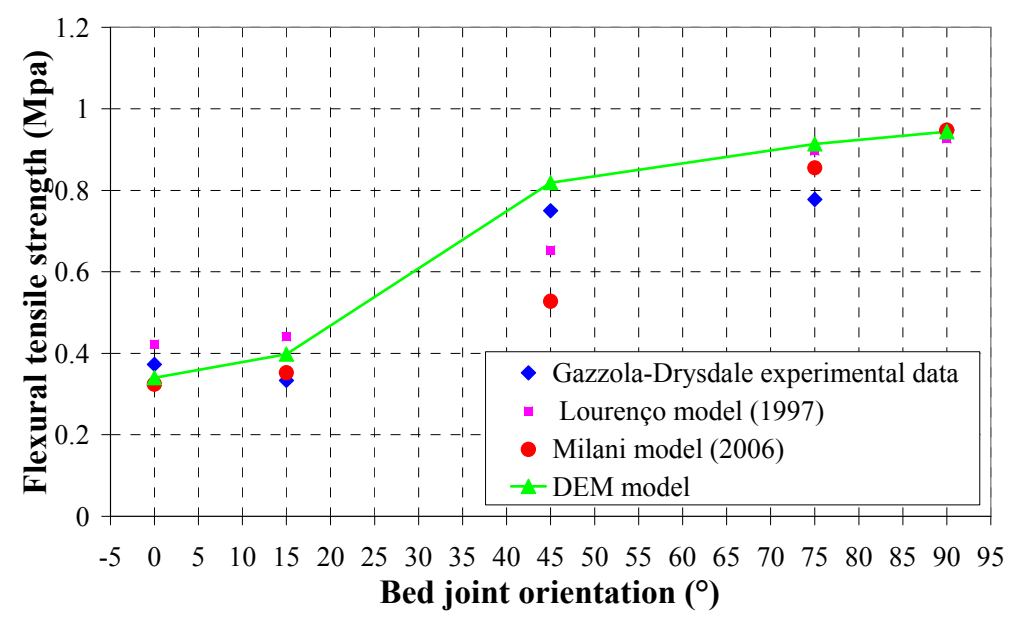

Figure 10: Flexural strength at different values of bed joint orientation.

The different flexural strength values showed in Figure 10, and obtained for the same masonry wall under lateral loading and for the same boundary conditions; confirms the complex behaviour mainly associated to the joints orientation. The results in Figure 10 show that the flexural strength for horizontal bending $\left(\theta=90^{\circ}\right)$ is approximately 2.5 times larger than the flexural strength for the vertical bending. The failure patterns obtained numerically (Figure 11) are quite representative of the experimental rupture modes given by Gazzola and Drysdale [8] [9].

a)

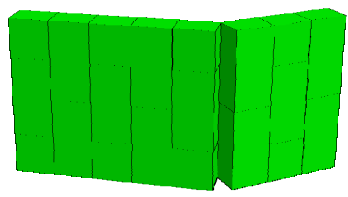

b)

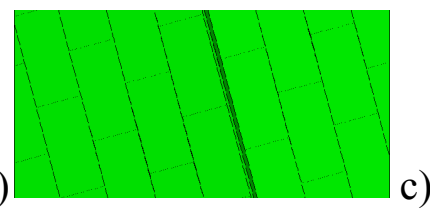

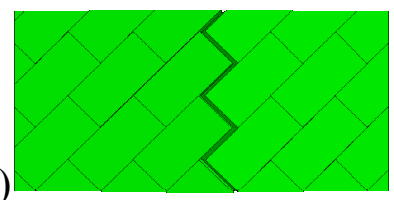

d)

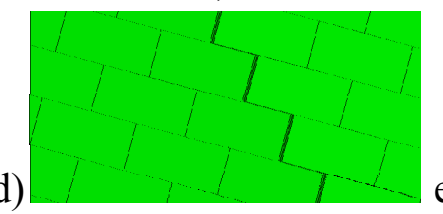

e)

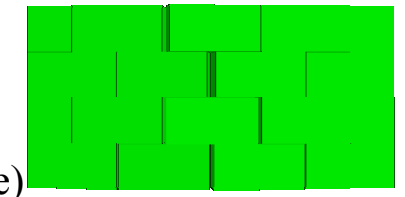

Figure 11: Failure patterns observed numerically according to joint orientation $\theta$ :
a) $\theta=0^{\circ}$;
b) $\theta=15^{\circ}$;
c) $\theta=45^{\circ}$;
d) $\theta=75^{\circ}$;
e) $\theta=90^{\circ}$. 


\subsection{Masonry wall under out-of-plane pressure: Experiment and DE Simulation}

When masonry infill panels are subjected to out-of-plane loading, they can be generally regarded as non-structural secondary elements or partially structural. The out-of-plane loading can be due to an overpressure due to blast effect induced by an explosion or the overpressure induced by impacts from a snow-avalanche if we consider the habitation in a mountain area, or more generally the effect of extreme wind. The objective of our experimental study is to analyse the behaviour of masonry walls subjected to a normal pressure, to characterise the failure mechanisms and to give an example for the simulation, then to gauge the effect of CFRP reinforcement, this last part will be discussed in an another paper.

\subsubsection{Test specimen, test setup and materials}

To reproduce in-situ conditions as closely as possible, a mason and his assistant were hired to construct the specimens. The test specimens intend to represent a portion of a typical load-bearing wall including corners, like in a low-rise building, or an individual house. As can be seen in Figure 12, for the two walls tested, the top remains free, while the bottom and two sides are supported. The geometrical dimensions of the wall, the nature of the units (standard hollow concrete blocks), as well as the presence of two return walls and of a reinforced concrete slab at base, respect the standards of construction. The most common construction materials are used, from the standard hollow concrete block to industrial ready-mix and bagconditioned mortar for the joints. The representative structure is a main wall $2.9 \times 2 \times 0.2 \mathrm{~m}$, subjected to an out-of-plane loading, and two internal or return walls on both edges $1.5 \times 2 \times 0.2 \mathrm{~m}$. With the aim of ensuring the boundary condition throughout the test, the lower bottom edges of the masonry walls were mortar bonded to the concrete rectangular slab support measuring $310 \times 185 \times 25 \mathrm{~cm}$ (length $\times$ width $\times$ height). The mock-ups include horizontal steel reinforcement ( 3 bars with a $6 \mathrm{~mm}$ diameter) at their top end inside the top bond beam, and vertical steel reinforcement ( 2 bars with a $12 \mathrm{~mm}$ diameter) at each corner, in accordance with the constructive process and standards. Only the units containing steel reinforcement were filled with concrete. The sizing of the steel rebar was calculated by considering the construction recommendations for habitation in mountain area, that is to say the ability to withstand a pressure induced by a snow-avalanche, of $300 \mathrm{mbars}$.

The main wall is subjected to a quasi-static loading of uniform pressure applied to the outside face, using six inflatable cushions or water-bags. The reaction wall (a reaction frame) consists of a set of metal beams HEB, anchored on the test slab of the laboratory by pre-stressed steel bars (Figure 13). 

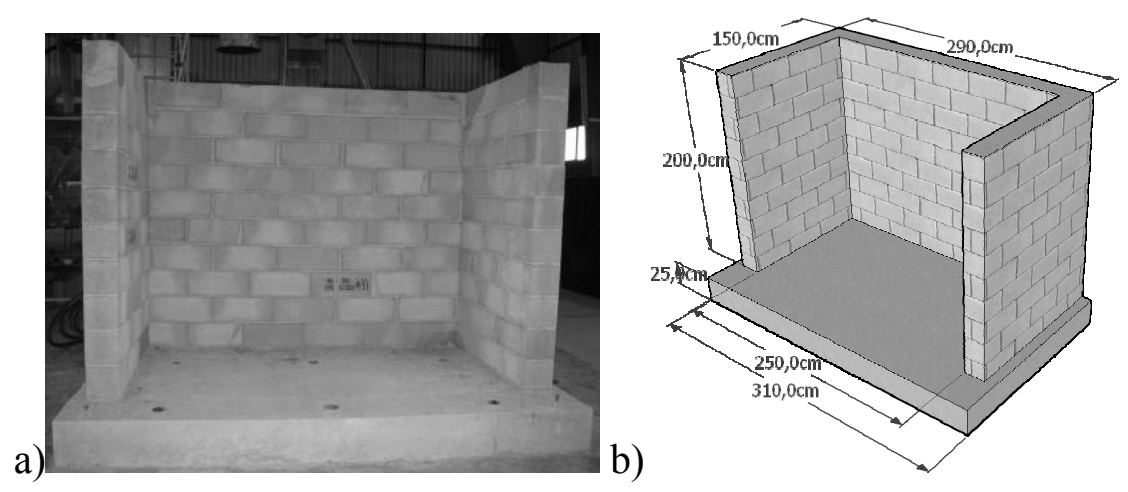

Figure 12: a) Masonry wall; b) Dimensions of the test specimen.

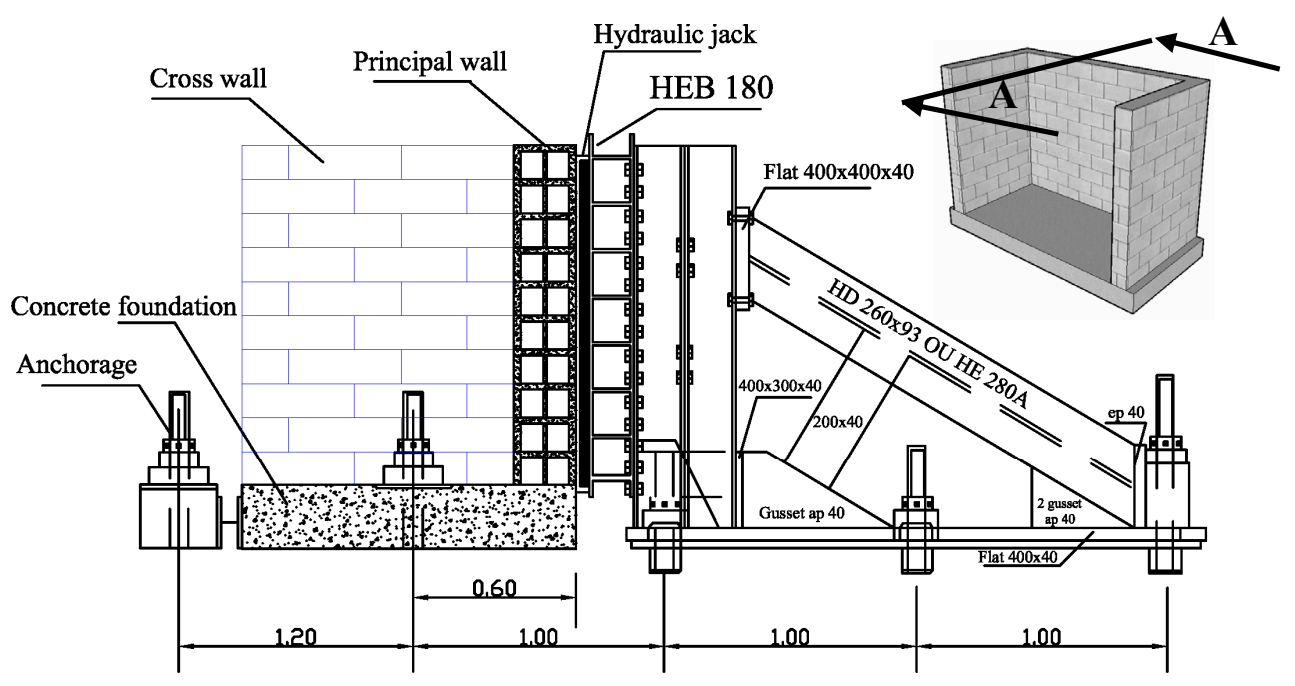

Figure 13: Laboratory test arrangement according to section AA

The out-of-plane displacement of the structure was measured using linear variable differential transducers (LVDT). Nine transducers were placed on the main wall (showed figure 14); three transducers were used to measure the displacement of the foundation. A pressure transducer was used to control and measure the applied water pressure. The positions of the transducers for each wall and the arrangement of the water-bags are shown in Figure 14:
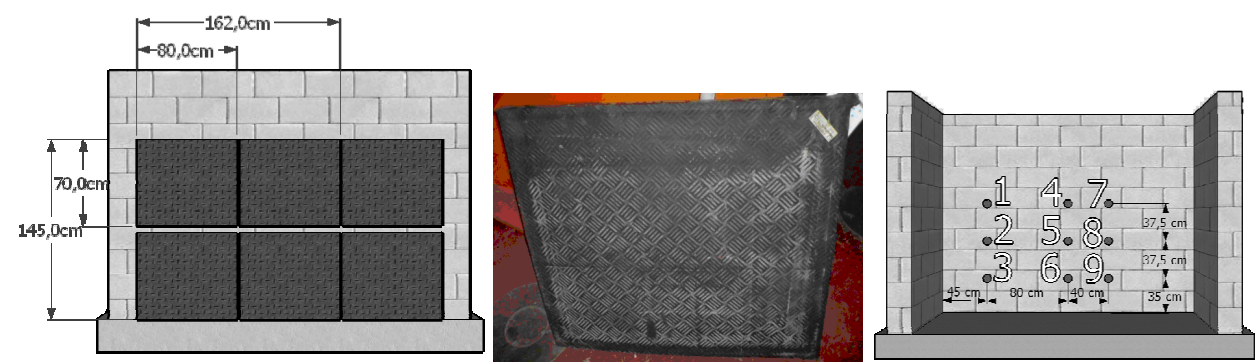

Figure 14: Water-bags (north side) and transducers positions (south side) 
A standard mortar (ready-mix mortar) was used in the construction of the masonry panels. Prismatic mortar specimens (dimensions 4x4x16 cm) were made to determine mechanical characteristics such as the compressive and the flexural strength. Each of these mortar specimens was tested right before the test was conducted on the structure. The average compressive strength and the mean flexural tensile strength obtained by testing 24 specimens were $16.5 \mathrm{MPa}$ (coefficient of variation $\mathrm{CV}=0.15)$ and $3.6 \mathrm{MPa}(\mathrm{CV}=0.16)$, respectively. The masonry units used were hollow concrete blocks of classification B40 in accordance to NF P 14-402. The nominal dimensions were $20 \mathrm{~cm}$ height, $50 \mathrm{~cm}$ length and $20 \mathrm{~cm}$ width. The uniaxial compression tests and masonry prism tests resulted in mean compressive strength, of $12.27 \mathrm{MPa}(\mathrm{CV}=0.07)$ and of $14.61 \mathrm{Mpa}(\mathrm{CV}=0.01)$ respectively, based on the net gross cross-sectional area. The concrete used for the reinforcement (the grout that was filled where the horizontal and vertical reinforcements were placed) and the slab support were C40/45 type. Compressive strength tests were carried out on $11 \mathrm{~cm}$ diameter $\mathrm{x} 22 \mathrm{~cm}$ high cylinders, the average stress obtained $43.18 \mathrm{MPa}$ is in adequacy with that awaited by the formulation.

\subsubsection{Test results}

A test of the unreinforced configuration was conducted to determine the bearing capacity and the modes of rupture. The pressure/deflection curve (Figure 15) shows quasi-linear behaviour up to a pressure intensity of about 340mbars, which corresponds to the onset of crack formation. A redistribution of the stresses, however, allows the load to increase until failure. The maximum pressure reached was 580mbars, and the maximum associated displacement, obtained in the central zone of the wall, was $26.7 \mathrm{~mm}$. The post-peak behaviour was characterized by a drop in the bearing capacity, but after this drop an increase of the load was observed until a plateau was reached. To avoid wall collapse, the loading process was stopped when the displacement reached $40 \mathrm{~mm}$ (obtained by transducer located at the middle of wall).

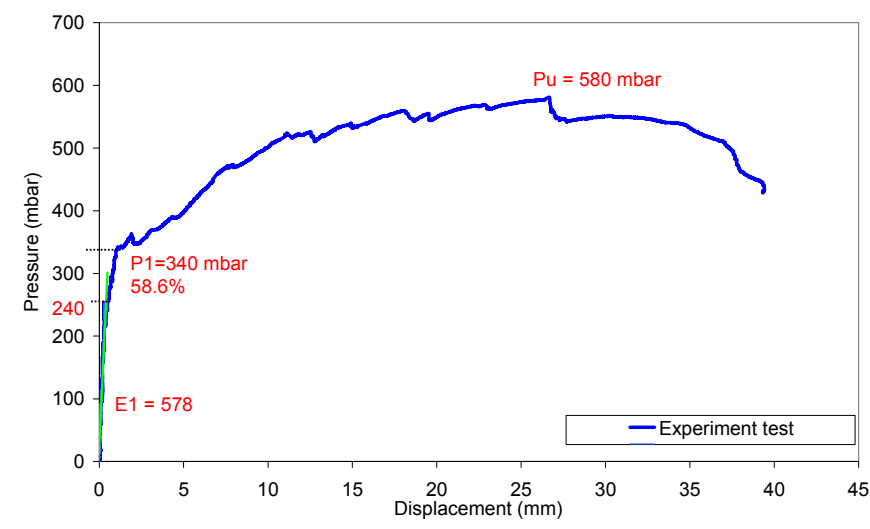

Figure 15: Experimental pressure/deflection curve obtained at mid-length 
Two types of cracks were observed on the main wall (Figure 16): first of all the vertical cracks which are characteristic of the bending loading. These cracks appeared near the centre of the wall, more or less at the midline in the upper part of the wall, which is unsupported. The second type of diagonal cracks formed in the lower part running from each corner. These crack patterns are similar to those predicted by the yield line theory adapted from that for reinforced concrete slabs. However, strictly speaking, yield line analysis is not applicable to a brittle material like masonry which cannot develop constant-moment hinges as occur in reinforced concrete with yielding of the steel [15].

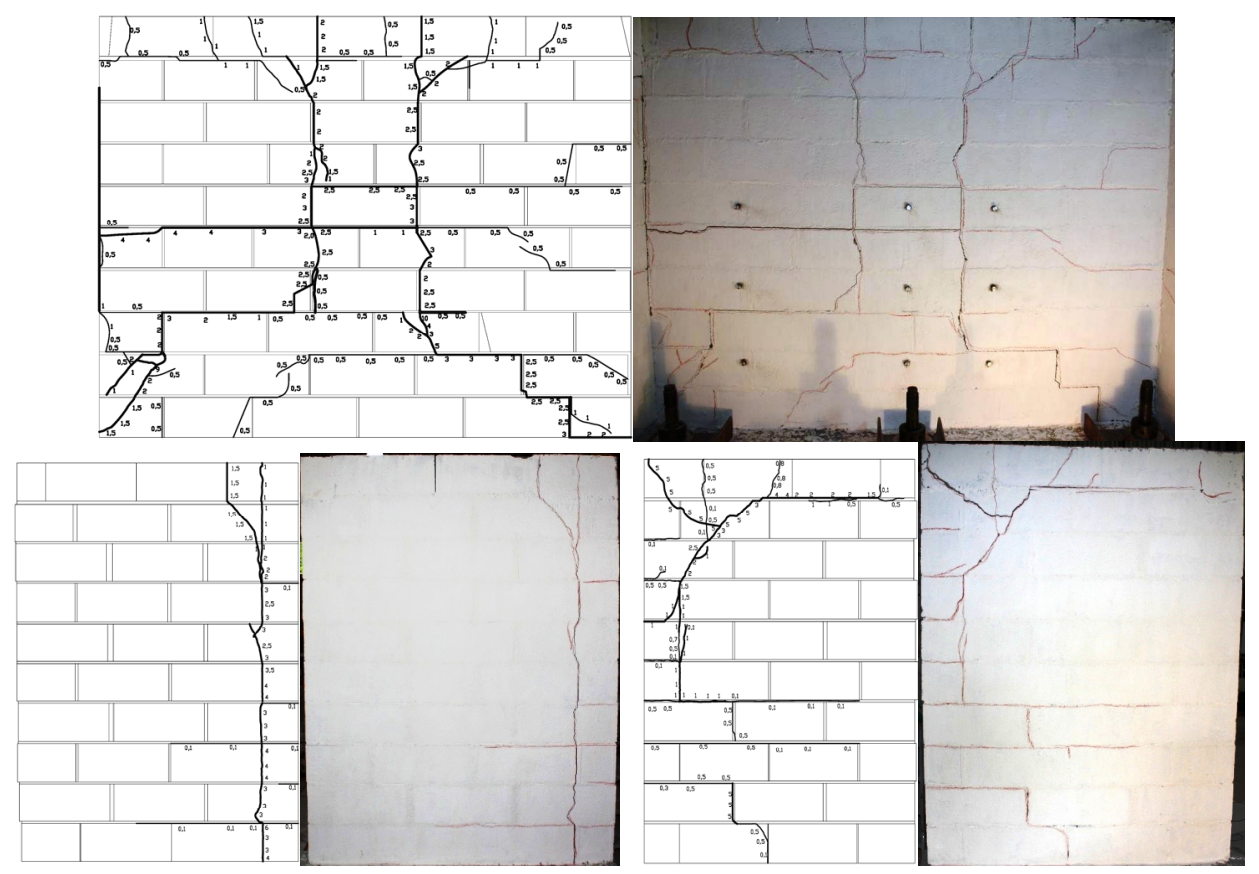

Figure 16: Failure modes of the principal walls and of two return walls.

At the final stage, important cracks were also observed on the return walls. First, vertical cracks appeared and propagated near the corner (intersection with the main wall). These cracks are due to the loading of the main wall which induces rotations at the level of corner posts (Figure 16). The return walls were also subjected to inplane shear which explains the appearance of diagonal cracks (Figure 16).

\subsubsection{Simulation results}

For the simulation the main and the two return walls are meshed by assembling blocks of size $0.5 \times 0.2 \times 0.2 \mathrm{~m}$ exactly in the same way as for the test (running bond). For the boundary conditions, an elastic concrete slab is modelled at the bottom of the wall, and clamped boundaries are considered at this level. Mechanical properties at failure adopted for the mortar joints and blocks are given in table below: 


\begin{tabular}{|c|c|c|c|c|c|c|c|c|}
\hline \multicolumn{4}{|c|}{ Block } & \multicolumn{7}{c|}{ Interface } \\
\hline Density & $\begin{array}{c}\text { Bulk } \\
\text { modulus }\end{array}$ & $\begin{array}{c}\text { Shear } \\
\text { modulus }\end{array}$ & $\begin{array}{c}\text { Normal } \\
\text { stiffness }\end{array}$ & $\begin{array}{c}\text { Tangent } \\
\text { stiffness }\end{array}$ & $\begin{array}{c}\text { Tensile } \\
\text { strength }\end{array}$ & Cohesion & $\begin{array}{c}\text { Friction } \\
\text { angle }\end{array}$ & $\begin{array}{c}\text { Dilatancy } \\
\text { angle }\end{array}$ \\
\hline$\left(\mathrm{kg} / \mathrm{m}^{3}\right)$ & $\begin{array}{c}\mathrm{K} \\
(\mathrm{MPa})\end{array}$ & $\begin{array}{c}\mathrm{G} \\
(\mathrm{MPa})\end{array}$ & $\begin{array}{c}k_{n} \\
(\mathrm{Gpa} / \mathrm{m})\end{array}$ & $\begin{array}{c}k_{s} \\
(\mathrm{Gpa} / \mathrm{m})\end{array}$ & $\begin{array}{c}\mathrm{T} \\
\left(\mathrm{N} / \mathrm{mm}^{2}\right)\end{array}$ & $\begin{array}{c}\mathrm{c} \\
\left(\mathrm{N} / \mathrm{mm}^{2}\right)\end{array}$ & $\begin{array}{c}\varphi \\
\left({ }^{\circ}\right)\end{array}$ & $\begin{array}{c}\psi \\
\left({ }^{\circ}\right)\end{array}$ \\
\hline 2500 & 3200 & 2700 & 14 & 14 & 0.3 & 0.45 & 48 & 36 \\
\hline
\end{tabular}

Horizontal and vertical reinforcement are modelled using 1D elements and their behaviour is considered elastic perfectly plastic (Figure 17). 1D element in 3DEC allows the modelling of a shearing resistance along their length, as provided by the shear resistance $\left(\mathrm{s}_{\mathrm{bond}}\right)$ between the grout. The cable is assumed to be divided into a number of segments of length to pass through the joints, with nodal points located at each segment end. Shearing resistance is represented by spring/slider connections $\left(\mathrm{k}_{\text {bond }} / \mathrm{s}_{\text {bond }}\right)$ between the structural nodes and the block zones in which the nodes are located. Tensile yield strength of steel reinforcement was taken equal to $400 \mathrm{MPa}$.

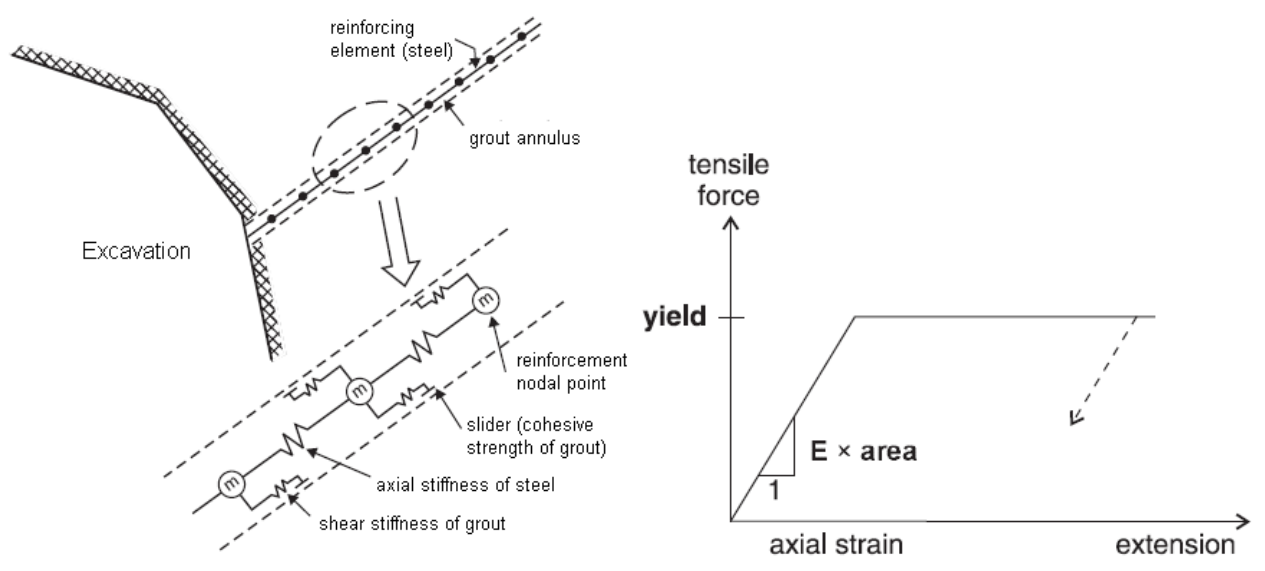

Figure 17: One-dimensional reinforcing element behaviour (Itasca) [12]

A high grout shear stiffness and cohesive strength are assigned to the $1 \mathrm{D}$ element nodes embedded in the blocks. The bond beam at the top of the walls contained three $6 \mathrm{~mm}$ diameter reinforcing elements. The vertical reinforcement element $(2$ bars with a $12 \mathrm{~mm}$ diameter) was at each corner.

First, model was brought to equilibrium under its own self weight. In order to determine the collapse pressure, the pressure-controlled was used. The load deflection curve obtained numerically is relatively close to the experimental one (Figure 18), and good agreement of the cracking pattern is also observed. 


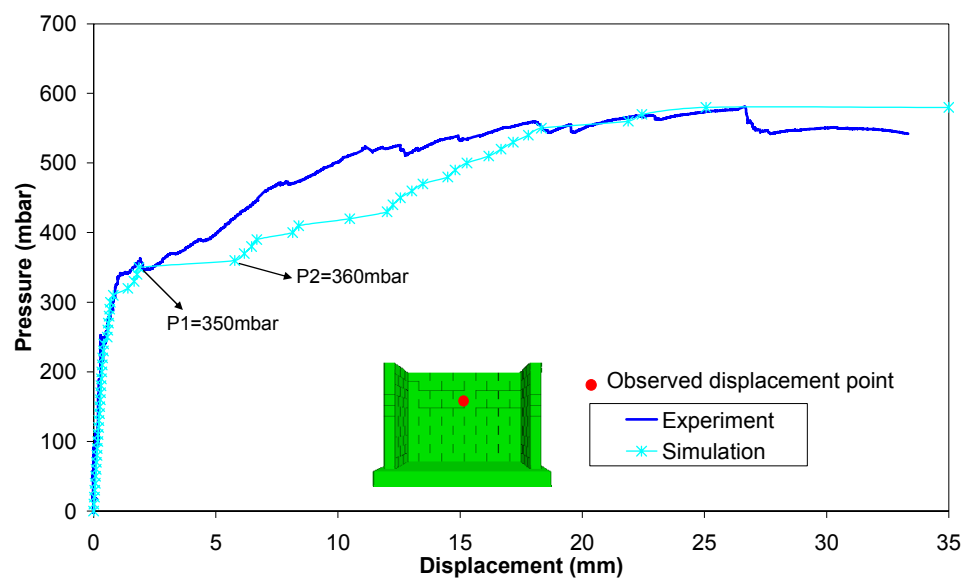

Figure 18: Pressure/deflection curve: comparison test/calculation.

In Figure 19, the first cracks at the beginning of rupture were presented in the main wall and the return wall.

a)

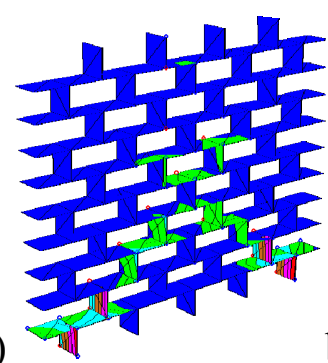

b)

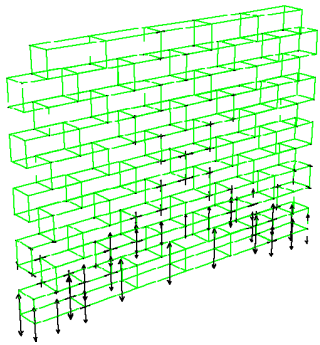

c)

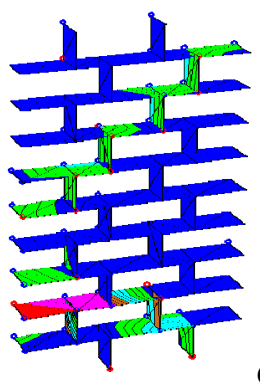

d)

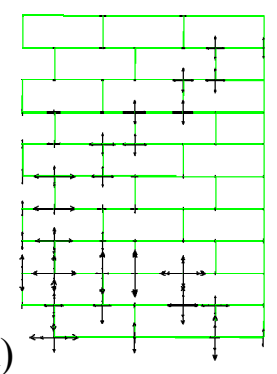

Figure 19: DEM: Fracture surface at $\mathrm{P}=350 \mathrm{mbar}$ (principal wall and return wall): a) c) Distribution of tangential displacements; b) d) Normal vectors at joints.

\section{Conclusion}

This research has been conducted to gauge the efficiency of DEM to reproduce the nonlinear behaviour of masonry walls subject to in plane or out of plane loads. Several experimental studies, some conducted by the authors, are simulated using the $3 \mathrm{DEC}$ code. The heterogeneous nature of masonry and the discontinuity at block interfaces can be well described using the discrete element approach. The numerical simulations provide good agreement with the experimental results. In particular, the simulations conducted allow us to qualify the bearing capacity of structures as well as the associated failure modes. The nonlinear behaviour observed in the experimental load-deflection curves are globally correctly reproduced from the initiation up to the final failure. This, ensures that crack appearance and propagation, are correctly reproduced. Stress redistributions inherent to cracks, are also correctly managed, which permits crack propagation and the final failure mechanism to be 
traced and the correct estimation of the bearing capacity as well as the characterisation of the collapse mode of the structure. In conclusion, the DEM is relevant for collapse simulation of masonry structures, where good quality results have been achieved. For masonry structures, the discrete element method allows for the simulation of rupture phenomenon and thus to manage discontinuities in an elegant and robust way.

\section{Acknowledgements}

Many thanks go to Mr. Bruno Hugueny and Mr Mario Masapollo (who helped also as an experienced mason) for their technical help during testing of the walls.

\section{References}

[1] P.B. Lourenço, J.G. Rots, "Multisurface interface model for analysis of masonry structures", ASCE J. Eng Mech, 123:660-8, 1997.

[2] P.B. Lourenço, "Aspects related to the out-of-plane numerical modeling of masonry", Mas Int, 14:31-4, 2000.

[3] J.G. Rots, "Structural masonry: an experimental/numerical basis for practical design rules", Rotterdam: Balkema, 1997.

[4] A. Munjiza, "The combined finite-discrete element method", New York: Wiley, 2004.

[5] T.T. Bui, A. Limam, D. Bertrand, E. Ferrier, M.Brun, "Masonry walls submitted to out-of-plane loading: Experimental and numerical study", Proceedings of the 8th International Masonry Conference in Dresden, 1153$1162,2010$.

[6] P.B. Lourenço, D.V. Oliveira, P. Roca, A. Orduna, "Dry Joint Stone Masonry Walls Subjected to In-Plane Combined Loading". Journal of Structural Engineering, Vol. 131, No. 11, 1665-1673, November 1, 2005.

[7] P.B. Lourenço. Computational strategies for masonry structures. PhD Thesis, Delft University of Technology, the Netherlands, 1996.

[8] E.A. Gazzola, R.G. Drysdale, A.S Essawy. Bending of concrete masonry walls at different angles to the bed joint. Proc. 3rd North. Amer. Mas. Conf., Arlington, TX, USA, Paper 27, 1985.

[9] E.A. Gazzola, R.G. Drysdale. A component failure criterion for blockwork in flexure. Proc., Structures 86 ASCE, S.C. Anand, ed., New Orleans, 134-153.

[10] P.B., Lourenço. An anisotropic macro-model for masonry plates and shells: Implementation and validation. Rep. No. 03.21.1.3.07, Univ. of Delft, Holland and Univ. of Minho, Guimaraes, Portugal, 1997.

[11] G. Milani, P.B. Lourenço, A. Tralli. Homogenization Approch for the Limit Analysis of Out-of-Plane Loaded Masonry Walls. Journal of Structural Engineering, Vol. 132, No. 10, Octobre 1, 2006.

[12] Itasca, 3DEC - Three Dimensional Distinct Element Code, Version 4.0, Itasca, Minneapolis, 2002. 
[13] L.F.Restrepo Vélez, G.Magenes. Static Tests on Dry Stone Masonry and Evaluation of Static Collapse Multipliers. Research Report ROSE 2010/02, Iuss Press, Pavia, Italy, 2010.

[14] D. D'Ayala, E. Speranza. Definition of collapse mechanisms and seismic vulnerability of masonry structures. Earthquake Spectra, Volume 19, Issue 3, 479-509, 2003.

[15] A.W. Hendry, B.P. Sinha, S.R. Davies, "Design of masonry structures", London: E\&FN Spon, 2004. 